\title{
STATIC CHARACTERISTICS OF THE FERROELECTRIC TRANSISTOR INVERTER
}

\author{
Cody Mitchell ${ }^{1}$, Crystal Laws ${ }^{1}$, Todd C. MacLeod ${ }^{2}$, Fat D. Ho ${ }^{1}$ \\ ${ }^{1}$ The University of Alabama in Huntsville, Department of Electrical and Computer Engineering, \\ Huntsville, Alabama 35899, USA \\ ${ }^{2}$ National Aeronautics and Space Administration, Marshall Space Flight Center, Huntsville, \\ Alabama 35812, USA
}

\begin{abstract}
The inverter is one of the most fundamental building blocks of digital logic, and it can be used as the foundation for understanding more complex logic gates and circuits. This paper presents the characteristics of an inverter circuit using a ferroelectric field-effect transistor. The voltage transfer characteristics are analyzed with respect to varying parameters such as supply voltage, input voltage, and load resistance. The effects of the ferroelectric layer between the gate and semiconductor are examined, and comparisons are made between the inverters using ferroelectric transistors and those using traditional MOSFETs.
\end{abstract}

Keywords: MOSFET, inverter, ferroelectric transistor 


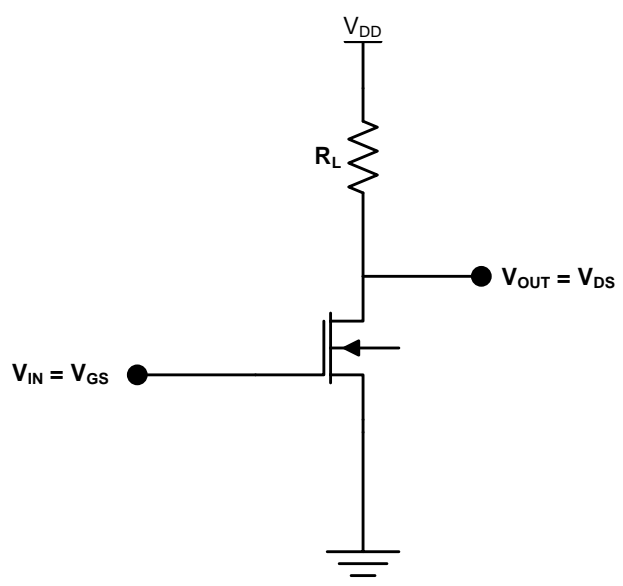

Figure 1. Circuit diagram of inverter using ferroelectric field-effect transistor

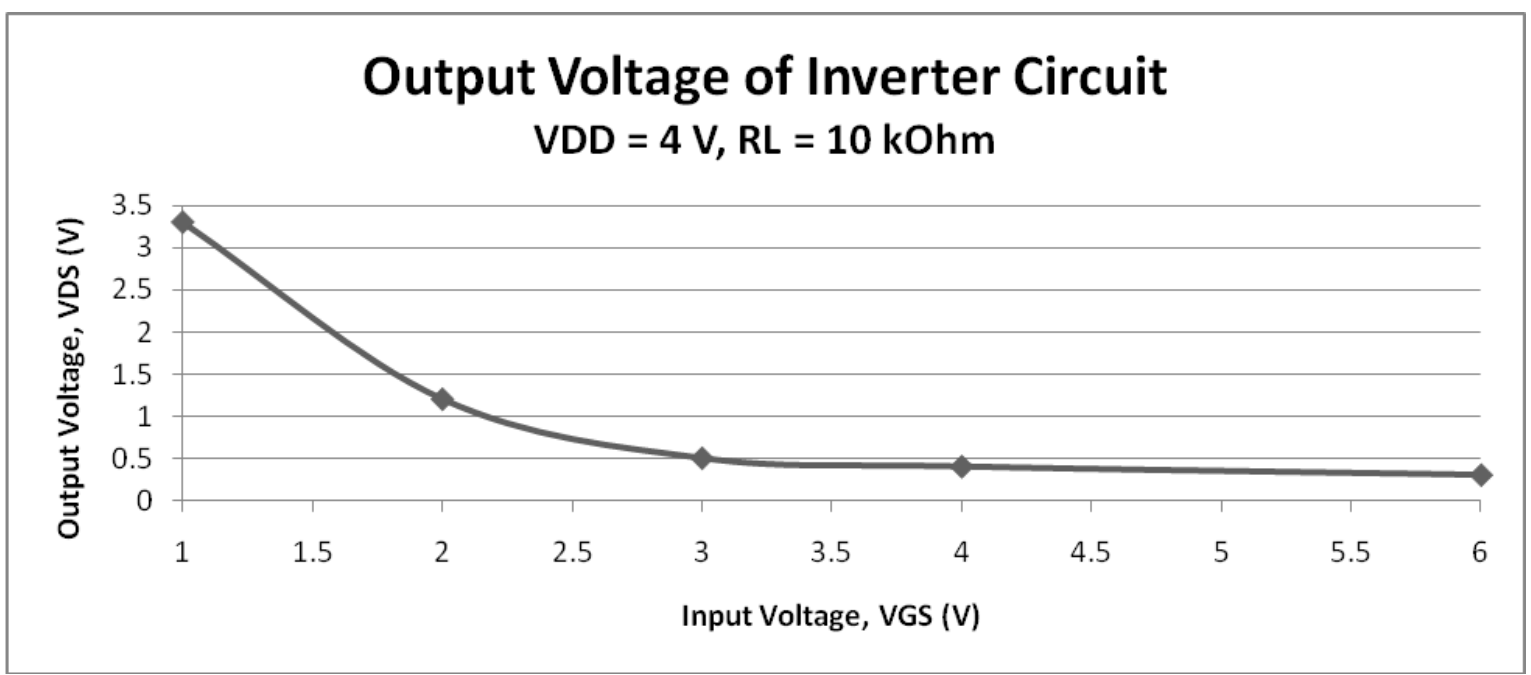

Figure 2. Output voltage of inverter using ferroelectric field-effect transistor, with supply voltage of $4 \mathrm{~V}$ and load resistance of $10 \mathrm{kOhm}$

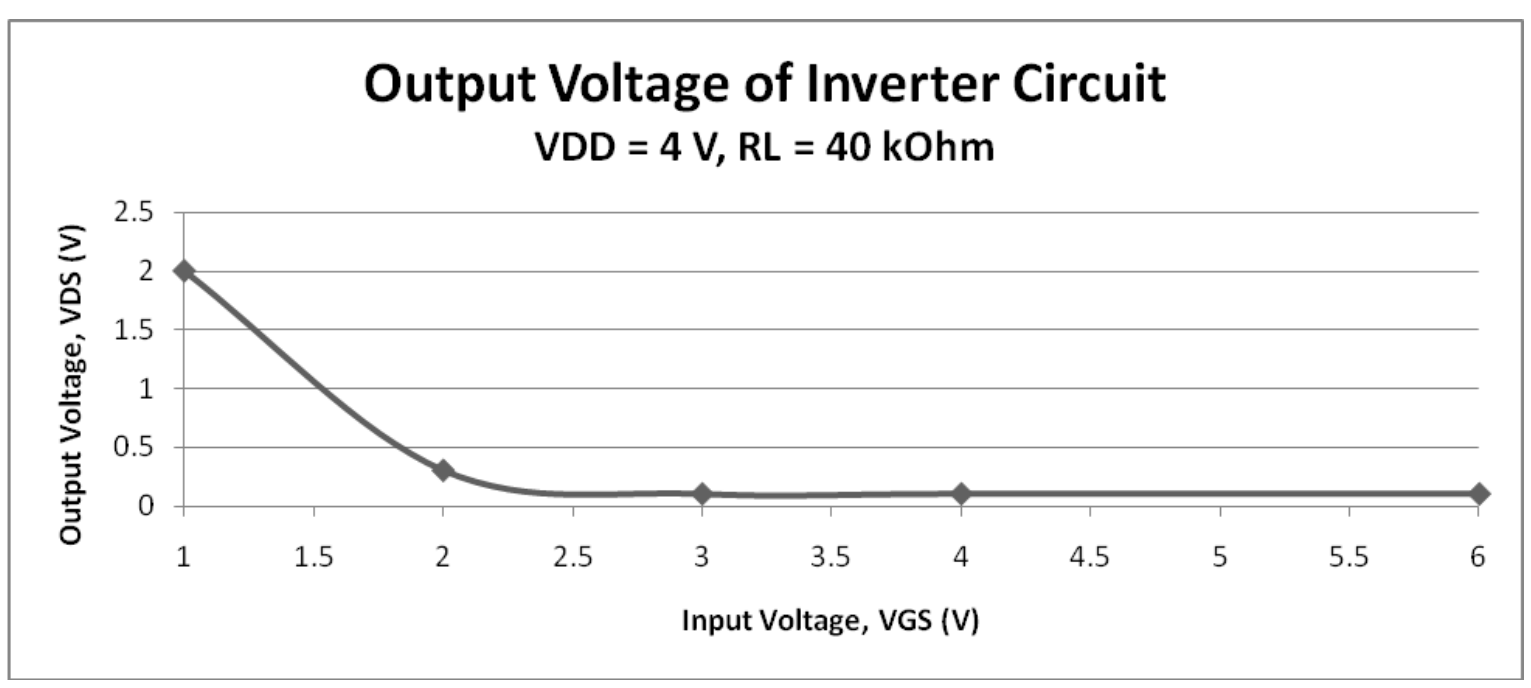

Figure 3. Output voltage of inverter using ferroelectric field-effect transistor, with supply voltage of $4 \mathrm{~V}$ and load resistance of $40 \mathrm{kOhm}$ 